\title{
Estudo metodológico sobre a substituição tributária
}

\author{
Juliano de Brito Neitzke ${ }^{1}$
}

\section{Resumo}

\begin{abstract}
Empreende um estudo metodológico sobre o instituto da substituição tributária. Inicia pelo estudo da estrutura sintática da norma jurídica. Delimita o subsistema do direito tributário, classificando as normas jurídicas que o constituem. Identifica a natureza jurídica dos denominados "deveres instrumentais". Em seguida, aborda a sujeição passiva tributária, enfatizando a substituição tributária. Por fim, constrói as regras matrizes que compõem o instituto da substituição tributária.
\end{abstract}

Palavras-Chave: Sujeição passiva tributária. Substituição tributária.

\section{Introdução}

Todo conhecimento a respeito de determinado objeto, que se pretenda científico, deve adotar um método de aproximação apto a conhecê-lo na sua inteireza, com a máxima fidelidade possível. E com a ciência do direito não é diferente. Se considerarmos que o sistema do direito positivo, seu objeto de estudo, constitui-se num corpo de linguagem, temos de levar em conta este dado no momento da escolha do método de investigação científica. E este método deve proporcionar, ao sujeito do conhecimento, todas as condições para que obtenha uma melhor apreensão desta característica ínsita ao direito.

Para nós, a metodologia adequada ao estudo científico do sistema do direito positivo é investigá-lo à luz da semiótica, ciência que tem por objeto de estudo os diversos sistemas de signos lingüísticos, vigorantes numa determinada sociedade, cujo objetivo é estudá-los sob três planos distintos: sintático, semântico e pragmático.

No presente estudo adotamos esta metodologia, com ênfase para o plano sintático. E o resultado, como não poderia ser diferente, revela-se fecundo e esclarecedor. $\mathrm{O}$ conhecimento da estrutura sintática da norma jurídica é fundamental no desenvolvimento do raciocínio jurídico desenvolvido. Isto porque permite visualizar, sob um enfoque mais preciso, os contornos do instituto da substituição tributária.

1 Especialista em Direito do Estado pela Universidade Estadual de Londrina. 


\section{A estrutura formal da norma jurídica}

Iniciamos o presente estudo fixando, como ponto de partida, a estrutura formal da norma jurídica.

Se adotarmos o símbolo $p$ para significar o antecedente ou hipótese, o símbolo $q$ para referir-se ao seu conseqüente ou tese e o símbolo lógico $(\rightarrow)$ para designar a relação implicacional entre eles existente, obteremos a fórmula da norma jurídica primária assim: “ $D$ $(p \rightarrow q)^{\prime \prime}$, onde $D$ é o functor (o sincategorema que indica a operação deôntica) incidente sobre a relação interproposicional. Esta é a fórmula utilizada pela lógica deôntica para descrever a estrutura sintática da norma jurídica primária.

A hipótese descreve um fato de possível ocorrência, mas não se preocupa com sua efetiva verificação. Nela residem conceitos, e estes são essencialmente seletores de propriedades. O real se apresenta na sua complexidade empírica e composição circunstancial infinita. Por certo que não é tudo do real que ingressa no universo do direito através da porta aberta que é a hipótese. Esta é qualificadora normativa do fáctico, tornando-o fato jurídico. A escolha sobre quais propriedades do fato entram e quais não entram representa o ato de valoração que preside à construção da norma jurídica, mais precisamente da hipótese.

Pontes de Miranda ensina que o

suporte factual, que está no mundo [...] não entra, sempre, todo ele. As mais das vezes, despe-se de aparências, de circunstâncias, de que o direito abstraiu; e outras vezes se veste de aparências, de formalismo, ou se reveste de certas circunstâncias, ficando estranhas a ele, para poder entrar no mundo jurídico. A própria morte não é fato que entre nu, em sua rudeza, em sua definitividade no mundo jurídico [... $]^{2}$

Contudo, observemos que se se dá, no plano da realidade, a ocorrência descrita na hipótese, esta não adquire o valor de verdadeira. Por outro giro, não será tida como falsa se nenhuma ocorrência vier a confirmar o descrito hipoteticamente. Como salienta Lourival Vilanova (1997, p. 87), "no descritor da norma jurídica inexiste juízo-derealidade subordinado ao critério de verificabilidade empírica para ser subsistente".

2 PONTES DE MIRANDA APUD VILANOVA, Lourival. As estruturas lógicas e o sistema do direito positivo. São Paulo: Max Limonad, 1997. p. 87-88. 
A proposição normativa em seu todo, constituída de hipótese ou descritor, e de conseqüência ou prescritor, é válida, antes de situação objetiva, fato natural ou fato humano de conduta, confirmar o que ela delineou. [...] O valer da hipótese e o valer da conseqüência cortam-se com outra norma válida. ${ }^{3}$

Já a tese ou conseqüente apresenta estrutura interna de proposição prescritiva. Prescreve uma relação jurídica entre um sujeito $S^{\prime}$ face outro sujeito $S^{\prime \prime}$ direcionados para um determinado objeto. O objeto da relação jurídica é a prestação de uma obrigação de dar, fazer ou não-fazer. Neste sentido, diz-se que a tese é proposição relacional.

Há entre estes sujeitos (termos da relação) o functor relacional $R$. Como ensina Lourival Vilanova (1997, p. 98), [este functor relacional] "não é descritivo. Não descreve relação existente, empiricamente dada ou formalmente necessária entre termos".

A relação $R$ é deôntica e se traduz por expressões deônticas: "está proibido", "está permitido", "está obrigado". $R$ é um dever-ser nessa tríplice modalidade, o resíduo formalizado que se obtém quando se desembaraçam as normas jurídicas positivas de seus revestimentos de linguagem natural.

Pensamos, juntamente com Paulo de Barros Carvalho, que a relação jurídica deve ser estudada, antes de tudo, e enquanto relação, à luz da Teoria dos Predicados Poliádicos ou Teoria das Relações, que é um capítulo da Lógica. Posteriormente é que, por imposição da própria ontologia do direito, se cogitará de suas especificidades.

Ora, seguindo a sorte dos predicados poliádicos, as relações estarão configuradas segundo uma combinatória estrita: um com um (uni-unívoca ou biunívoca), um com vários (uni-plurívoca), vários com um (pluriunívoca) ou vários com vários (pluriplurívoca). Não há outras combinações possíveis, o que significa declarar que, ao elaborar os enunciados prescritivos do direito posto, o legislador será prisioneiro dessa angusta possibilidade combinatória.

A relação poderá ser reflexiva ou irreflexiva, simétrica ou assimétrica, transitiva ou intransitiva, qualidades perante as quais as relações se posicionam. Caso dependesse do quadro das possibilidades tão-somente lógicas e a relação jurídica poderia, perfeitamente, ser reflexiva. Todavia, por referência à região de objetos a que pertence, que é o campo material das condutas intersubjetivas, não haverá reflexividade nas relações jurídicas. Ninguém pode entrar em relação jurídica consigo mesmo. E o direito positivo, intuindo esse obstáculo, alude à "confusão", para dizer que o vínculo ficará extinto caso o sujeito que ocupe a posição sintática de predecessor venha a ocupar, também, a de sucessor $(x \mathrm{R} x)$. E outro tanto ocorre com a simetria. As relações jurídicas serão sempre assimétricas, isto é, inexistirá identidade entre a relação originária e sua conversa: ( $x$ Ro y) $\neq$ (y Rc x). Se x é mutuante em face de $y$, então y será mutuário diante de $x$. E ser mutuante é

3 VILANOVA, 1997. p. 87. 
diferente de ser mutuário. Se x é vendedor para com y, então y será comprador em relação a $x$.

Por outro lado, se a relação jurídica não pode ser reflexiva ou simétrica, nada impede que seja transitiva. Toda vez que o legislador entender por bem de fazê-lo, poderá construir uma relação transitiva, do tipo $(x>y)$, ou decretá-la como tal, na conformidade do que acontece na sentença de falência, na concordata e no concurso de credores ${ }^{4}$.

Em conclusão, podemos afirmar que, observando a estrutura formal da norma jurídica, constatamos a existência de um functor deôntico incidindo na relação-deimplicação entre hipótese e tese e outro functor deôntico no interior da estrutura relacional da tese. Formalizando: " $D(p \rightarrow q)$ ", sendo $p$ proposição descritiva e $q$ proposição prescritiva.

Investigando o interior de $q$, temos $S^{\prime}, R, S^{\prime \prime}$, onde $R$ é a variável functoral, cujos valores substituintes são as constantes deônticas permissão, proibição e obrigação $(P, V, O)$.

No que tange à norma jurídica secundária que, associada à primária, formam a norma jurídica completa, temos que a estrutura sintática é a mesma, ou seja, um antecedente implicando um conseqüente. Entretanto, no antecedente da norma jurídica secundária encontramos a descrição do descumprimento do dever estatuído no consequente da norma primária, que poderemos representar pelo símbolo -q. Já, em seu conseqüente, há a prescrição de uma relação jurídica que deverá ser instaurada entre o Estado-juiz e os sujeitos da relação jurídica prevista na norma primária, cujo objeto é a prestação da tutela jurisdicional consubstanciada na aplicação de uma sanção, que representaremos pelo símbolos.

A norma jurídica completa, portanto, pode ser expressa da seguinte forma: $D(p \rightarrow q)$ $v(-q \rightarrow s)$. O conectivo que relaciona a norma primária e a norma secundária é o ou (v). Será o ou excludente se estivermos considerando a norma jurídica quanto a sua aplicação: ou aplica-se a norma primária, ou a secundária, excluindo-se a aplicação simultânea de ambas. Será o ou includente se estivermos considerando a norma jurídica quanto a sua validade: ambas deverão ser válidas.

Com isso, chegamos à

forma da juridicidade: tipifica o incontávelmente diferente das ações humanas, vincula a tais tipos conseqüências também típicas, como tipifica o antijurídico que serve de pressuposto às sanções (civis, penais, administrativas, políticas). Com essa

4 CARVALHO, Paulo de Barros. Curso de direito tributário. 13. ed. São Paulo: Saraiva, 2000. p. 29-30. 
esquematização dos fatos, uns diferentes dos outros, consegue o direito orientar a conduta humana, compondo a ordem jurídica, eliminando o caos a que levaria terse de fazer uma norma para cada fato, um preceito para cada ação, uma regra para cada conduta ${ }^{5}$.

\section{Subsistema do direito tributário}

O subsistema do direito tributário é composto por normas jurídicas que versam "matéria tributária", independentemente do grau hierárquico em que se encontrem: é esta a sua referência comum.

Se classificarmos as normas jurídicas tributárias utilizando-nos como critério de diferenciação o grupo institucional a que pertencem, poderemos agrupá-las em três classes:

a) normas que demarcam princípios, concebidos para dar os limites da virtualidade legislativa no campo tributário;

b) normas que definem a incidência do tributo, equivale a dizer, descrevem fatos e estipulam os sujeitos da relação, como também os termos determinativos da dívida (norma padrão de incidência ou regra-matriz da incidência tributária). Cabem nessa rubrica as normas que instituem isenções, bem como as regras sancionatórias;

c) normas que fixam outras providências administrativas para a operatividade do tributo, tais como as de lançamento, recolhimento, configuração de deveres instrumentais e relativas à fiscalização. ${ }^{6}$

\subsection{Deveres instrumentais}

Ladeando a obrigação tributária, que realiza os anseios do Estado, enquanto entidade tributante, dispõe a ordem jurídica sobre comportamentos outros, positivos ou negativos, consistentes num fazer ou não-fazer, que não se explicam em si mesmos, preordenados que estão a facilitar o conhecimento, o controle e a arrecadação da importância devida como tributo.

Tais relações são conhecidas pela designação imprecisa de obrigações acessórias, nome impróprio, uma vez que não apresentam o elemento caracterizador dos laços obrigacionais, inexistindo nelas prestação passível de transformação em termos pecuniários. São liames concebidos para produzirem o aparecimento de deveres jurídicos, que os súditos do Estado hão de observar, no sentido de imprimir efeitos práticos à percepção dos tributos ${ }^{7}$.

E ao atribuir uma denominação a estas relações jurídicas, Paulo de Barros Carvalho afirma que prefere a expressão "deveres instrumentais" ou "deveres formais".

VILONOVA, 1997. p. 23.

CARVALHO, 2000. p. 235.

Idem. p. 284-285. 
Deveres, com o intuito de mostrar, de pronto, que não têm essência obrigacional, isto é, seu objeto carece de patrimonialidade. E instrumentais ou formais porque, tomados em conjunto, é o instrumento de que dispõe o Estado-Administração para o acompanhamento e consecução dos seus desígnios tributários. Ele (Estado) pretende ver atos devidamente formalizados, para que possa saber da existência do liame obrigacional que brota com o acontecimento fáctico, previsto na hipótese da norma.

Encarados como providências instrumentais ou como a imposição de formalidades, tais deveres representam o meio de o Poder Público controlar o fiel cumprimento da prestação tributária, finalidade essencial na plataforma da instituição do tributo ${ }^{8}$.

\subsection{Sujeição passiva tributária}

Se focalizarmos, dentre as normas constituintes do sistema tributário, apenas as regras-matrizes de incidência fiscal - denominação que Paulo de Barros Carvalho confere à norma jurídica instituinte de tributo -, teremos como único e possível sujeito passivo o contribuinte, ou seja, aquele que realiza o critério material da hipótese. É importante consignar que o contribuinte é o titular do dever jurídico de dar ao sujeito ativo certa quantia em dinheiro, suportando o ônus econômico da exação fiscal.

Agora, o contribuinte não é o único sujeito passivo que podemos extrair do contexto do subsistema tributário total. Isto porque o Código Tributário Nacional, em seu art. 128, prescreve o seguinte:

Art. 128. Sem prejuízo do disposto neste Capítulo, a lei pode atribuir de modo expresso a responsabilidade pelo crédito tributário a terceira pessoa, vinculada ao fato gerador da respectiva obrigação, excluindo a responsabilidade do contribuinte ou atribuindo-a a este em caráter supletivo do cumprimento total ou parcial da referida obrigação.

Ao comentar este dispositivo legal, Paulo de Barros Carvalho observa que

ao ler o versículo, vertido numa linguagem suficientemente clara, prepara-se o intérprete para assimilar um princípio genérico, que o ajude a compreender as mensagens subseqüentes, reguladoras da responsabilidade dos sucessores, da responsabilidade de terceiros e da responsabilidade por infrações. E sua expectativa não se vê frustrada, porquanto há, verdadeiramente, um enunciado geral, firmando diretriz, acompanhado de uma ressalva que serve de suporte aos arts. 129 usque $138^{9}$.

CARVALHO, 2000. p. 287.

CARAVALHO, 2000. p. 314. 
A doutrina tradicional do direito tributário, ao tratar do tema relativo a responsabilidade tributária, classifica-a em "responsabilidade por transferência", "responsabilidade por cumulação" e "responsabilidade por substituição".

Entretanto, não adotamos tal classificação e entendemos que foge aos objetivos do presente trabalho explicarmos os motivos de nossa discordância. Por isso, restringimo-nos tão somente a afirmar que, de acordo com o nosso ponto de vista, a responsabilidade tributária é diferente da substituição tributária, de tal sorte que esta não pode ser considerada como espécie daquela. Agora, uma coisa é certa, têm em comum a circunstância de serem, ambas, espécies de sujeição passiva tributária.

Desta forma, podemos dizer que há, em nosso sistema jurídico tributário, três espécies de sujeitos passivos tributários: o contribuinte, o responsável e o substituto.

No que concerne à figura da responsabilidade tributária, mais uma vez para que não fujamos do tema a que nos propomos desenvolver, remetemos o leitor às lições de Paulo de Barros Carvalho, que sistematiza brilhantemente a matéria. Fixemo-nos, a partir de agora, na figura da substituição tributária.

\subsection{Substituição tributária}

O instituto da substituição desfruta de grande atualidade no Brasil, difundindo-se intensamente como vigoroso instrumento de controle racional e de fiscalização eficiente no processo de arrecadação dos tributos. Entretanto, ao mesmo tempo em que responde aos anseios de conforto e segurança das entidades tributantes, provoca sérias dúvidas no que concerne aos limites jurídicos de sua abrangência e à extensão de sua aplicabilidade. Afinal de contas, o impacto da percussão fiscal mexe com valores fundamentais da pessoa humana - propriedade e liberdade -, de tal sorte que não se pode admitir transponha o legislador certos limites, representados por princípios lógico-jurídicos e também jurídico-positivos ${ }^{10}$.

E um destes limites jurídicos encontra-se plasmado no art. 128 do Código Tributário Nacional, que é, justamente, o fundamento de validade do instituto em estudo. Do texto do referido dispositivo legal extraímos o entendimento de que tal limite, a rigor, consiste na demarcação do universo de pessoas que poderão figurar como substitutos tributários, restringindo a escolha do legislador apenas dentre aquelas vinculadas ao evento que serve de substrato à descrição fática contida na hipótese tributária, com exceção do

10 CARVALHO, Paulo de Barros. Direito Tributário - fundamentos jurídicos da incidência. São Paulo: Saraiva, 1999. p. 161. 
contribuinte. Como se vê, temos, aqui, importante regra de estrutura que influi decisivamente nos contornos do instituto da substituição tributária.

Portanto, podemos concluir que a substituição tributária só pode ser instituída para aqueles tributos cuja descrição hipotética, contida no suposto normativo, tenha como substrato um evento passível de vinculação com pelo menos duas pessoas: o contribuinte e uma outra qualquer. Esta é uma conclusão lógica, resultante do limite jurídico acima enunciado.

E a experiência jurídica nos permite afirmar que este evento haverá de ser, forçosamente, relacional. Consistirá numa relação jurídica cujos termos serão o contribuinte e uma outra pessoa qualquer. E é sobre esta outra pessoa, e somente esta, que poderá recair o ônus da substituição tributária, caso assim deseje o legislador. Utilizemo-nos de dois exemplos para ilustrar o que vimos afirmando:

Se considerarmos o imposto sobre circulação de mercadorias (ICM), teremos em sua hipótese tributária a seguinte descrição: realizar operação relativa à circulação de mercadoria, no território do Estado, reputando-se acontecido o evento no átimo da saída das mercadorias do estabelecimento comercial. Vejamos que a hipótese tributária, aqui, descreve a celebração de um negócio jurídico que se dá, obviamente, entre pelo menos duas pessoas. Mas no critério pessoal da norma tributária encontraremos qual delas será o contribuinte do ICM. E à outra pessoa, por estar vinculada ao evento que serve de suporte à descrição da hipótese tributária, poderá recair o ônus da substituição tributária.

Agora, se considerarmos o antecedente normativo da regra matriz de incidência do imposto de renda (IR), teremos a seguinte descrição hipotética: auferir renda, no território nacional, reputando-se ocorrido o evento no instante da obtenção da renda.

Conforme podemos perceber, a descrição hipotética não se refere, aqui, à celebração de um negócio jurídico. Refere-se a uma conduta que ocorrerá com a concretização de uma relação jurídica (evento) que the serve de substrato: aquela que legitima a obtenção de renda. E nesta relação jurídica há quem recebe a renda e quem paga a renda. Agora, se na própria hipótese já há a descrição da conduta de quem recebe a renda, este é quem será o contribuinte.

Portanto, o ônus da substituição tributária só poderá recair sobre quem paga a renda. 
$\mathrm{Na}$ verdade, a substituição tributária caracteriza-se como uma técnica de arrecadação de tributos, por meio da qual o substituto atua como um verdadeiro agente arrecadador, a serviço do sujeito ativo tributário.

Via de regra, cabe ao contribuinte pagar, diretamente ao sujeito ativo tributário, a quantia pecuniária devida a título de tributo. Entretanto, por meio da substituição tributária se insere um intermediário entre o contribuinte e o sujeito ativo tributário. O contribuinte pagará, então, a quantia relativa ao tributo para o intermediário, e este é quem fará a entrega do dinheiro ao sujeito ativo tributário. O intermediário de que falamos é o substituto; e o contribuinte é o substituído.

Ocorre, portanto, uma substituição da pessoa que fará a entrega, ao sujeito ativo tributário, de certo valor em dinheiro a título de tributo. E isto não implica em substituição do pólo passivo da obrigação tributária, que continua inalterada. O contribuinte é e sempre será o devedor tributário, verdadeiro titular da capacidade contributiva.

Diante do exposto, podemos concluir que a técnica da substituição tributária pressupõe o surgimento de mais dois vínculos jurídicos, além da obrigação tributária: um entre o substituto e o sujeito ativo tributário, via de regra o Estado; outro entre o substituto e o substituído, via de regra o contribuinte.

E para que possamos visualizar, com absoluta precisão, a compostura deste instituto jurídico tributário, construiremos as regras matrizes que, ao nosso ver, o constituem.

\subsection{Regras matrizes da substituição tributária}

Traçando um paralelo com a teoria de Paulo de Barros Carvalho a respeito da regra matriz de incidência fiscal, do instituto da substituição tributária podemos extrair três regras matrizes distintas, mas somente duas aplicar-se-ão conjuntamente, numa relação de coordenação.

Uma delas contém o dever instrumental, atribuído ao substituto, de entregar certa quantia em dinheiro a título de tributo, proveniente do contribuinte, ao sujeito ativo tributário. A esta regra atribuiremos a denominação de regra matriz determinante da substituição tributária. Determinante porque é em razão dela que, logicamente, instala-se 
uma das outras duas regras matrizes da substituição tributária, que denominaremos de determinadas.

E é nas regras matrizes determinadas da substituição tributária que encontraremos o mecanismo, outorgado ao substituto, que o permite extrair dinheiro do substituído (contribuinte) relativo ao tributo devido por este ao sujeito ativo tributário.

E conforme já restou assinalado linhas acima, o substituto e o substituído (contribuinte) mantêm, entre si, uma relação jurídica que serve de substrato à descrição hipotética do antecedente da regra matriz de incidência tributária. E nesta relação jurídica, que será obrigatoriamente de cunho econômico, teremos o substituído como credor ou como devedor do substituto.

Caso o substituído seja credor do substituto, o mecanismo apto a permitir que este extraia dinheiro daquele será atribuindo-lhe o dever de retenção do equivalente ao débito tributário. Agora, se o substituído for devedor do substituto, tal mecanismo será o de outorgar ao substituto o dever de acrescer ao débito do substituído o valor correspondente ao tributo. E caso haja o descumprimento, por parte do substituto, destes deveres instrumentais, tornar-se-á responsável tributário.

Como se vê, por meio da substituição tributária o Estado intervém em determinadas relações jurídicas, modificando-as em seu objeto, para garantir o recebimento do crédito tributário. E esta providência estatal deve-se à constatação, junto à realidade social, de que os particulares, principalmente nas relações comerciais e trabalhistas, via de regra preferem honrar com as relações jurídicas de natureza privada do que com as obrigações tributárias.

\subsubsection{Regra matriz determinante da substituição tributária}

Esta norma jurídica tem a natureza de um dever instrumental, pois prescreve uma obrigação de fazer que se destina a contribuir para uma maior eficiência da arrecadação tributária.

Em sua hipótese normativa há a descrição de um fato em que o correspondente evento que the serve de substrato consiste numa relação jurídica de conteúdo econômico, que se dá entre o contribuinte e o substituto tributário. E esta relação jurídica é a mesma 
que serve de suporte fáctico para a hipótese tributária - antecedente da regra matriz de incidência fiscal.

Agora, quando a hipótese normativa da substituição tributária não se referir diretamente ao negócio jurídico celebrado entre o contribuinte e o substituto, referir-se-á à conduta praticada pelo substituto, que é prescrita por aquela relação jurídica (evento), a que nos referimos.

E no que tange ao conseqüente normativo, precisamente em seu critério pessoal, temos que o sujeito ativo é o mesmo da regra matriz de incidência tributária, e o sujeito passivo é o substituto tributário que, como já foi afirmado, atua como um verdadeiro agente arrecadador de tributos.

O objeto da relação jurídica (prestação) delineada no consequente normativo é fazer, modalizado deonticamente com o operador obrigatório: obrigação de fazer a entrega do dinheiro devido pelo contribuinte ao sujeito ativo. E o objeto da prestação, portanto, é dinheiro, consistente na quantia calculada conforme o critério quantitativo da regra matriz de incidência fiscal.

Como se vê, o substituto arrecada parcela do patrimônio de outrem (contribuinte) para fazer a entrega ao sujeito ativo tributário. É por este motivo que defendemos que não se trata de obrigação de dar, pois este tipo de prestação pressupõe a entrega de coisa própria, e não de coisa alheia.

Caso a prestação fosse um dar por parte do substituto e, portanto, tendo ele que retirar de seu patrimônio quantia referente a tributo devido por outrem (contribuinte), estaríamos diante de um empréstimo compulsório, cujo ressarcimento dar-se-ía quando o substituto repercutisse o valor pago a título de tributo sobre o substituído. E fosse assim, estaríamos presenciando uma afronta ao princípio da capacidade contributiva, pois o substituto não poderia ser compelido a possuir patrimônio suficiente a suportar a carga tributária incidente sobre a capacidade econômica de terceira pessoa. Isto porque, evidentemente, ninguém é obrigado a ter igual patrimônio ao daquele com quem se relaciona juridicamente.

Sobre o assunto, Paulo de Barros Carvalho, em nota de roda pé, assevera que

quando se faz referência a entregas de dinheiro ao Estado, comportamento que realiza a prestação tributária, é sumamente importante salientar que a quantia 
entregue deve sair do patrimônio do sujeito passivo. Do contrário, não teremos tributo, mas outro tipo de relação jurídica. É o caso do chamado 'imposto de renda na fonte'. Não cremos existir relação jurídica tributária entre a União e a empresa que retém, mas tão-somente uma obrigação estabelecida pelo legislador federal, com a finalidade de facilitar o cumprimento da prestação, a cargo do verdadeiro sujeito passivo (a pessoa física que teve parte de seu dinheiro retida na fonte pagadora). E por isso que é dever, de conteúdo patrimonial, há penalidades pecuniárias que garantem ao Estado o cumprimento dessa prestação por parte das pessoas jurídicas que devam promover a retenção.

É curioso notar que quase todos os autores se referem a esse tipo de vínculo como sendo de índole tributária ${ }^{11}$.

Diante do exposto, teremos a estrutura lógica desta regra matriz formalizada da seguinte maneira:

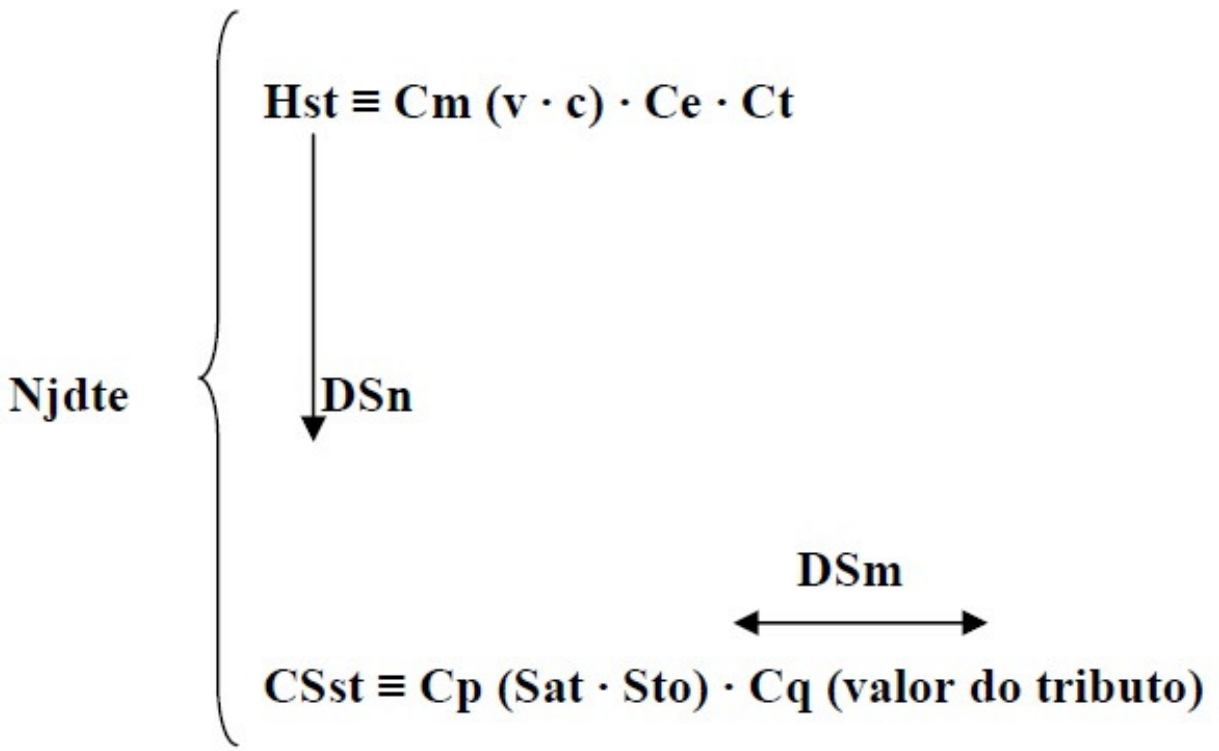

Explicação dos símbolos:

11 CARVALHO, Paulo de Barros. Teoria da norma tributária. 4. ed. São Paulo: Max Limonad, 2002. p. 89. 


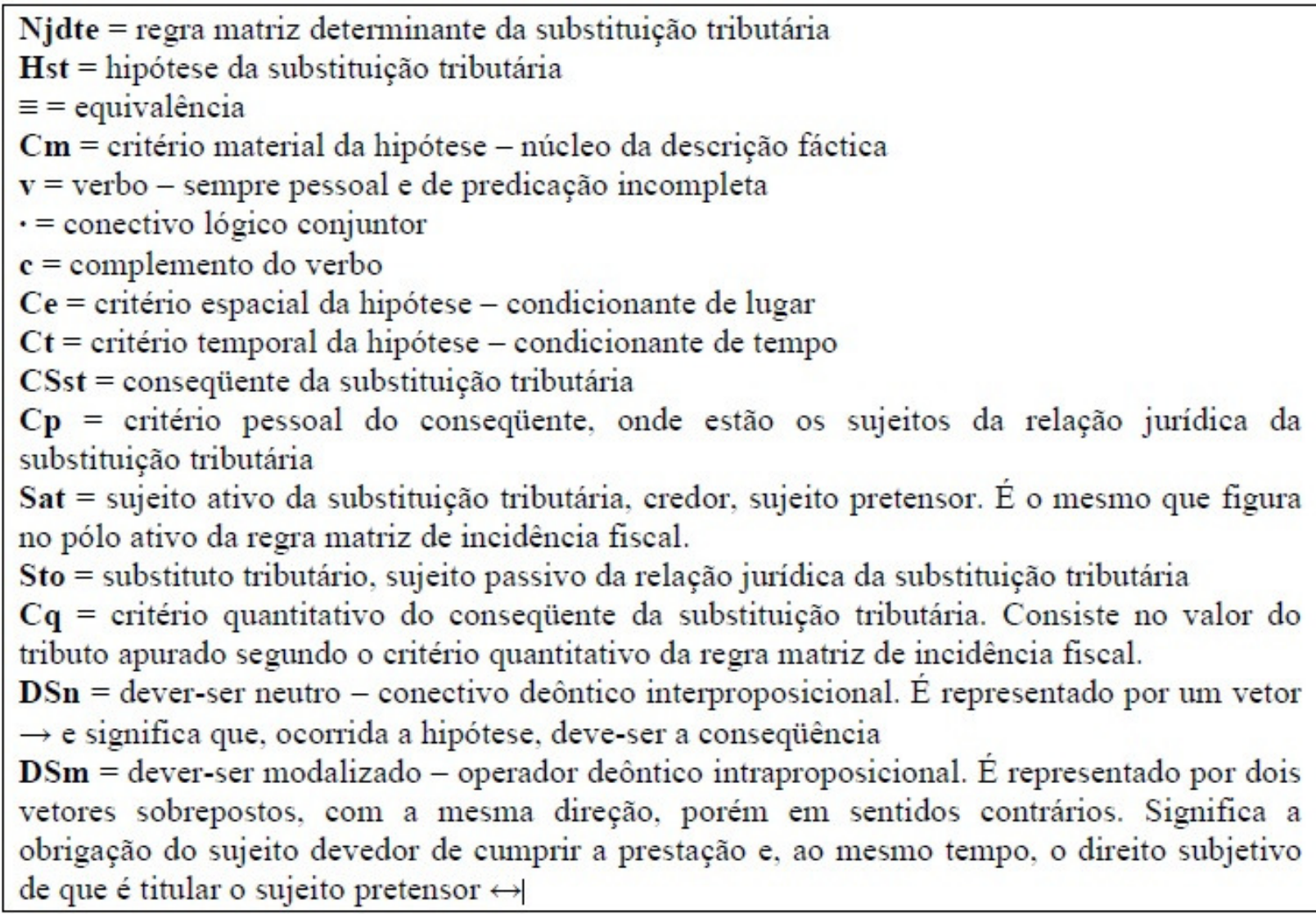

\subsubsection{Regra matriz determinada da substituição tributária - dever de retenção}

Esta é uma das duas normas jurídicas destinadas a permitir que o substituto arrecade dinheiro do substituído (contribuinte). Também possui a natureza jurídica de um dever instrumental.

Incidirá quando o substituto for devedor do substituído naquela relação jurídica que se constitui no evento que serve de substrato à descrição hipotética, contida no antecedente da norma padrão determinante da substituição tributária. Com isso, terá o substituto dever de reter parcela de seu débito perante o substituído, exonerando-se da obrigação com o pagamento de uma parte dela. E o valor retido, que corresponde ao débito tributário do substituído, será entregue pelo substituto ao sujeito ativo tributário.

A hipótese desta norma jurídica consiste na descrição da relação jurídica, delineada no conseqüente da regra matriz determinante da substituição tributária, instaurada entre o substituto e o sujeito ativo tributário. 
E no que diz respeito à tese desta norma de direito, precisamente em seu critério pessoal, temos que o sujeito ativo é o substituído tributário (contribuinte) e o sujeito passivo é o substituto tributário.

O objeto da relação jurídica (prestação) delineada no consequente normativo é fazer, modalizado deonticamente com o operador obrigatório: obrigação de fazer a retenção do tributo. E o objeto da prestação é dinheiro, equivalente ao valor do tributo devido pelo substituído tributário.

Entendemos que a realização da conseqüência desta norma jurídica enseja a simultânea extinção da obrigação tributária, pelo pagamento do tributo ao substituto (agente de arrecadação). Agora, se o substituto vai ou não entregar ao sujeito ativo tributário o dinheiro retido do contribuinte, é outro problema, que a este não diz mais respeito.

Formalizando esta regra matriz determinada da substituição tributária, teremos o seguinte:

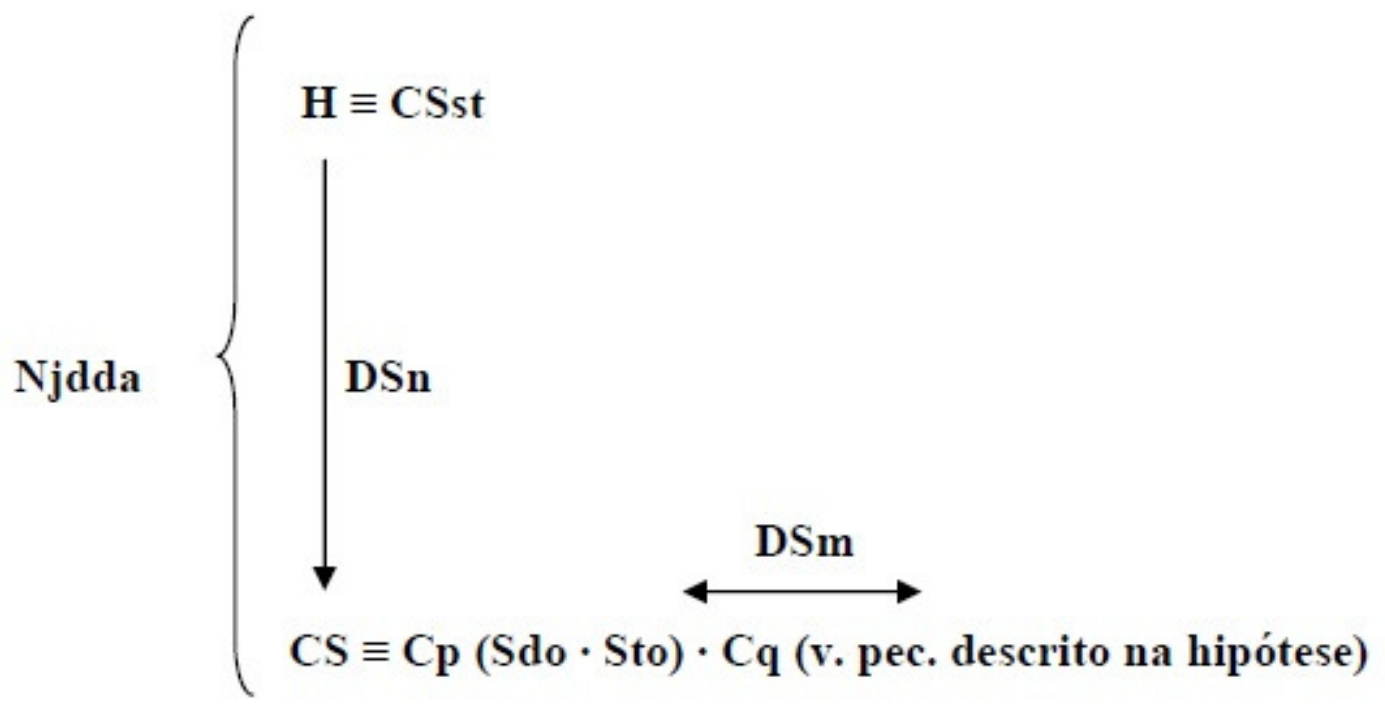

Explicação dos símbolos: 
Njdda = regra matriz determinada da substituição tributária

$\mathbf{H}=$ hipótese

CSst = conseqüente da regra matriz determinante da substituição tributária

$\equiv=$ equivalência

$\cdot=$ conectivo lógico conjuntor

$\mathrm{CS}=$ conseqüente

$\mathbf{C} \mathbf{p}=$ critério pessoal do conseqüente, onde estão os sujeitos da relação jurídica

Sdo $=$ substituído tributário, sujeito ativo da relação jurídica

Sto $=$ substituto tributário, sujeito passivo da relação jurídica

$\mathbf{C q}=$ critério quantitativo - indicador da fórmula de determinação do objeto da prestação.

Corresponde ao mesmo valor pecuniário descrito na hipótese

DSn = dever-ser neutro - conectivo deôntico interproposicional. É representado por um vetor $\rightarrow$ e significa que, ocorrida a hipótese, deve-ser a conseqüência

DSm = dever-ser modalizado - operador deôntico intraproposicional. É representado por dois vetores sobrepostos, com a mesma direção, porém em sentidos contrários. Significa a obrigação do sujeito devedor de cumprir a prestação e, ao mesmo tempo, o direito subjetivo de que é titular o sujeito pretensor $\leftrightarrow$

\subsubsection{Regra matriz determinada da substituição tributária - dever de acréscimo do valor do tributo}

E esta é a outra norma jurídica que se destina a permitir que o substituto arrecade dinheiro do substituído (contribuinte). Também possui a natureza jurídica de um dever instrumental. Incidirá quando o substituto for credor do substituído naquela relação jurídica que se constitui no evento que serve de substrato à descrição hipotética, contida no antecedente da norma padrão determinante da substituição tributária. Com isso, terá o substituto o dever de acrescer ao seu crédito perante o substituído o valor devido por este a título de tributo. E o substituído só estará exonerado da obrigação com o pagamento de todo o débito, (quantia original mais débito tributário). Posteriormente, o valor correspondente ao débito tributário do substituído será entregue, pelo substituto, ao sujeito ativo tributário.

A hipótese desta norma jurídica consiste na descrição da relação jurídica, delineada no conseqüente da regra matriz determinante da substituição tributária, instaurada entre o substituto e o sujeito ativo tributário.

E no que diz respeito à tese desta norma de direito, precisamente em seu critério pessoal, temos que o sujeito ativo é o substituído tributário (contribuinte) e o sujeito passivo é o substituto tributário. 
O objeto da relação jurídica (prestação) delineada no consequente normativo é fazer, modalizado deonticamente com o operador obrigatório: obrigação de fazer o acréscimo do valor do tributo. E o objeto da prestação é dinheiro, equivalente ao valor do tributo devido pelo substituído tributário.

Quando o substituído adimplir o seu débito perante o substituto, ocorrerá a simultânea extinção da obrigação tributária, pelo pagamento do tributo ao substituto tributário (agente de arrecadação instituído por Lei).

E a regra matriz apresentará a seguinte fórmula:

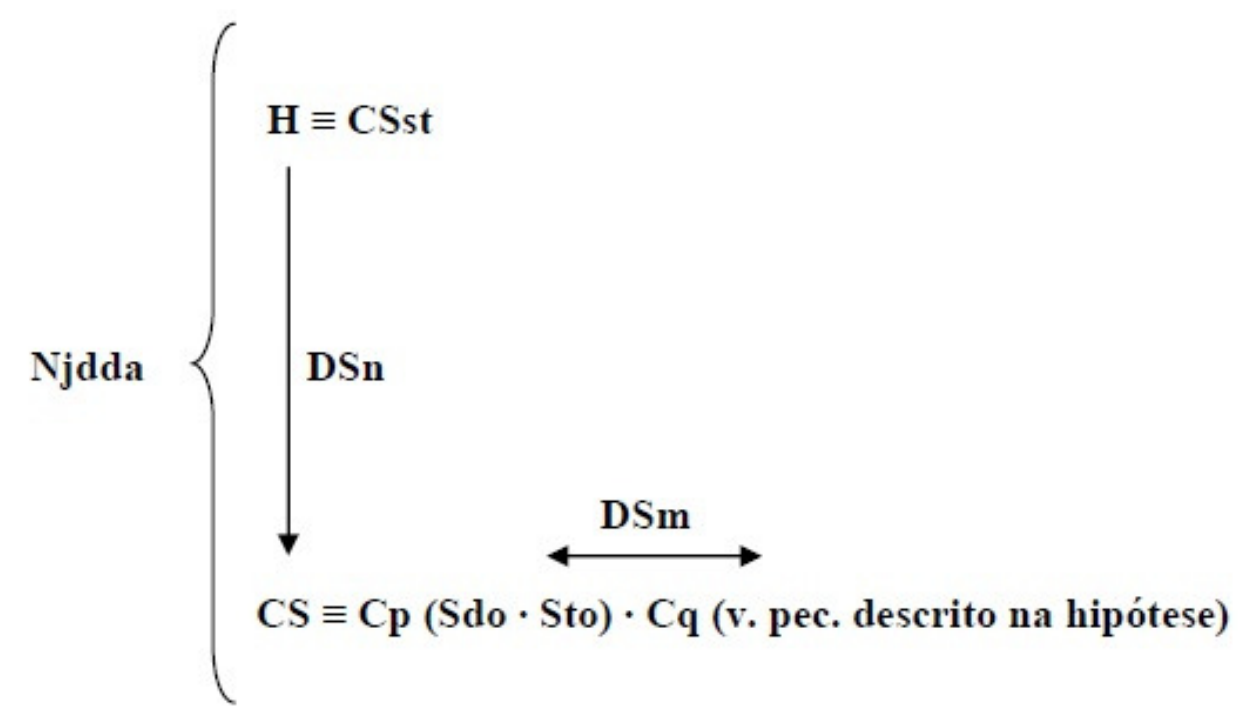

Explicação dos símbolos: 
Njdda $=$ regra matriz determinada da substituição tributária

$\mathbf{H}=$ hipótese

CSst $=$ conseqüente da regra matriz determinante da substituição tributária

$\equiv=$ equivalência

$\cdot=$ conectivo lógico conjuntor

$\mathrm{CS}=$ conseqüente

$\mathbf{C p}=$ critério pessoal do conseqüente, onde estão os sujeitos da relação jurídica

Sdo = substituído tributário, sujeito ativo da relação jurídica

Sto $=$ substituto tributário, sujeito passivo da relação jurídica

$\mathbf{C q}=$ critério quantitativo - indicador da fórmula de determinação do objeto da prestação.

Corresponde ao mesmo valor pecuniário descrito na hipótese

DSn $=$ dever-ser neutro - conectivo deôntico interproposicional. É representado por um vetor $\rightarrow$ e significa que, ocorrida a hipótese, deve-ser a conseqüência

DSm $=$ dever-ser modalizado - operador deôntico intraproposicional. É representado por dois vetores sobrepostos, com a mesma direção, porém em sentidos contrários. Significa a obrigação do sujeito devedor de cumprir a prestação e, ao mesmo tempo, o direito subjetivo de que é titular o sujeito pretensor $\leftrightarrow$

\section{Conclusão}

1. Substituição tributária é espécie de sujeição passiva tributária. Entretanto, o substituto tributário não se confunde com o contribuinte e nem com o responsável tributário. Desta forma, podemos dizer que há, em nosso sistema jurídico tributário, três espécies de sujeitos passivos tributários: o contribuinte, o responsável e o substituto.

2. $\mathrm{O}$ art. 128 do Código Tributário Nacional constitui-se em importante limite á instituição da substituição tributária. Tal dispositivo legal demarca o universo de pessoas que poderão figurar como substitutos tributários, restringindo a escolha do legislador apenas dentre aquelas vinculadas ao evento que serve de substrato à descrição fática contida na hipótese tributária, com exceção do contribuinte.

3. A substituição tributária caracteriza-se como uma técnica de arrecadação de tributos, por meio da qual o substituto atua como um verdadeiro agente arrecadador, a serviço do sujeito ativo tributário. E a técnica da substituição tributária pressupõe o surgimento de mais dois vínculos jurídicos, além da obrigação tributária: um entre o substituto e o sujeito ativo tributário, via de regra o Estado; outro entre o substituto e o substituído, via de regra o contribuinte.

4. Do instituto da substituição tributária podemos extrair três regras matrizes distintas, mas somente duas aplicar-se-ão conjuntamente, numa relação de coordenação. 
Uma delas contém o dever instrumental, atribuído ao substituto, de entregar certa quantia em dinheiro a título de tributo, proveniente do contribuinte, ao sujeito ativo tributário: é a regra matriz determinante da substituição tributária. Determinante porque é em razão dela que, logicamente, instala-se uma das outras duas regras matrizes da substituição tributária, denominadas de determinadas. E é nas regras matrizes determinadas da substituição tributária que encontraremos o mecanismo, outorgado ao substituto, que o permite extrair dinheiro do substituído (contribuinte) relativo ao tributo devido por este ao sujeito ativo tributário: dever de retenção ou dever de acréscimo do valor do tributo.

\section{Referências}

CARVALHO, Paulo de Barros. Curso de direito tributário. 13. ed. São Paulo: Saraiva, 2000. Direito tributário: fundamentos jurídicos de incidência. 2. ed. São Paulo: Saraiva, 1999. . Teoria da norma tributária. 4. ed. São Paulo: Max Limonad, 2002.

VILANOVA, Lourival. As estruturas lógicas e o sistema do direito positivo. São Paulo: Max Limonad, 1997. . Fundamentos do Estado de Direito. Revista de Direito Público, São Paulo,v. 8, n. 43/44, p. 21-31, 1977. 